\title{
Valence - Réaménagement de la place Juiverie
}

Opération préventive de diagnostic (2013)

\section{Pascale Réthoré}

\section{(2) OpenEdition \\ 1 Journals}

\section{Édition électronique}

URL : http://journals.openedition.org/adlfi/14860

ISSN : 2114-0502

Éditeur

Ministère de la Culture

Référence électronique

Pascale Réthoré, « Valence - Réaménagement de la place Juiverie » [notice archéologique], ADLFI. Archéologie de la France - Informations [En ligne], Auvergne-Rhône-Alpes, mis en ligne le 20 mai 2015, consulté le 25 février 2021. URL : http://journals.openedition.org/adlfi/14860

Ce document a été généré automatiquement le 25 février 2021.

(C) ministère de la Culture et de la Communication, CNRS 


\section{Valence - Réaménagement de la place Juiverie}

Opération préventive de diagnostic (2013)

\section{Pascale Réthoré}

\section{NOTE DE L'ÉDITEUR}

Organisme porteur de l'opération : Inrap

1 Ce petit sondage de $55 \mathrm{~m}^{2}$ a permis d'observer un développement stratigraphique quasi complet et caractéristique de l'urbanisme valentinois. Il est très similaire, dans ses grandes lignes, à celui dégagé lors des fouilles du Musée de Valence. Il y manque néanmoins les niveaux précoces. Recoupant les sols fersialitiques würmiens qui marquent la terrasse alluviale sur laquelle est construite Valence, la semelle de fondation d'un mur de type monumental, orienté nord-sud, large de 1,57 m, montée en moellons de petit appareil de grés calcaire a été mise au jour. Le niveau de dérasement de ce mur cote à 125,60 m. Il n'existe aucun sol en lien avec lui. Il a vraisemblablement été détruit au cours de l'Antiquité tardive. Ainsi, ce mur «flotte » dans le temps, entre les niveaux géologiques würmiens et le $\mathrm{II}^{\mathrm{e}} \mathrm{s}$. On peut simplement supposer qu'il se situe au Haut-Empire. Sa situation topographique corroborerait l'hypothèse d'un forum, avec les bâtiments monumentaux qui l'entourent, proposée par A. Blanc (Blanc 1964, p. 60). Ce mur monumental pourrait appartenir à l'un d'eux. La tranchée de spoliation d'un mur perpendiculaire au mur monumental nord-sud traduit une modification probable de ce premier bâti monumental à partir du $\mathrm{III}^{\mathrm{e}} \mathrm{s}$. Une reprise est éventuellement perceptible aussi aux $\mathrm{IV}^{\mathrm{e}}-\mathrm{V}^{\mathrm{e}} \mathrm{s}$. Il faut attendre le Moyen Âge classique pour que ce mur soit vraiment détruit. Cette période du Moyen Âge se caractérise par des terres de jardins qui se développent sur près de $0,80 \mathrm{~m}$. Ce phénomène est récurrent dans le sous-sol de Valence, au point que l'on s'interroge sur la place de l'habitat de cette période, jamais touché par nos interventions archéologiques. En revanche, c'est sans doute à partir du bas Moyen Âge qu'apparaît un premier habitat dont les murs et les 
sols externes ont pu être observés. Le bâtiment sera associé à un jardin pourvu d'une citerne à l'époque moderne. Cet immeuble perdurera jusqu'aux grands bouleversements urbains du XIX ${ }^{\mathrm{e}}$ s., avant de devenir la place actuelle au Xxe $\mathrm{s}$.

\section{INDEX}

chronologie https://ark.frantiq.fr/ark:/26678/pcrtxT02uJOogm, https://ark.frantiq.fr/ark:/ 26678/pcrtof7EHNsS2e, https://ark.frantiq.fr/ark:/26678/pcrtZTmusVUU24

Année de l'opération : 2013

nature https://ark.frantiq.fr/ark:/26678/pcrtWWQS75V5Bc

lieux https://ark.frantiq.fr/ark:/26678/pcrtSEeAipsBlD, https://ark.frantiq.fr/ark:/26678/ crtB8WDyqd6u9, https://ark.frantiq.fr/ark:/26678/pcrtKgdLgiLWKX, https://ark.frantiq.fr/ark:/ 26678/pcrtwtyAN6Y1rr

sujets https://ark.frantiq.fr/ark:/26678/pcrtKJVpuP3AET, https://ark.frantiq.fr/ark:/26678/ pcrtM9HMWQTGJV, https://ark.frantiq.fr/ark:/26678/pcrtDpSNLz1mSr, https://ark.frantiq.fr/ ark:/26678/pcrtIxHmbVwDYW, https://ark.frantiq.fr/ark:/26678/pcrtE2HKmkY7aj, https:// ark.frantiq.fr/ark:/26678/pcrtDlzbGxWvTo, https://ark.frantiq.fr/ark:/26678/pcrtbptj4SOA1W

\section{AUTEURS}

\section{PASCALE RÉTHORÉ}

Inrap 